\title{
THE INCITEMENT TO FIELDWORK
}

Ward Keeler

\begin{abstract}
Fieldwork necessarily causes some degree of psychological stress for an ethnographer, although the nature and consequences of such stress vary individually. Rather than lament or conceal that fact, I suggest that an ethnographer's idiosyncratic responses can provide particular insights. To illustrate the point, I consider what might have induced me, and perhaps others, to take on the necessarily disorienting role of an ethnographer. I then contrast my experience (as a middle-aged Western anthropologist) of a meditation retreat in Burma with my experience (as a recently divorced bisexual man) of a naked men's yoga retreat in Texas. These brief vignettes are intended to suggest that my specific personal conflicts alert me to matters of more general anthropological interest.
\end{abstract}

Keywords: Burma, fieldwork, meditation, reflexivity, sexuality

The critique of anthropology has since its beginnings in the 1980s generated a few well-rehearsed assertions, or admonitions, focusing on the need for ethnographers to bear in mind the power differential between themselves and the people they are likely to want to learn about. Suppressing information about how the fieldwork encounter actually took place, this well-known critique asserts, dissembles the power imbalance between the anthropologist and his or her objects of study (cf. Clifford and Marcus 1986; Marcus and Fischer 1986). Keeping the pridefulness of researchers in check is certainly worthwhile. Yet there is another dimension to the matter of fieldwork encounters that tends to get lost in the handwringing about anthropologists' hubris, as it tends also to get lost in the claims made for ethnographies written in a personal voice: the obvious fact that every anthropologist takes a psyche to the field.

I use the word 'psyche' as a shorthand reference to the accumulating effects on a person's relations with the world that his or her individual, idiosyncratic experiences will generate. Such an inference about how individuals' thinking and 
acting bears the imprint of their prior interactions-most significantly, although by no means exclusively, those early in their lives-may well be a culture-bound understanding. It is clear to me that I, a middle-class American, subscribe to this view with greater conviction than the people I speak with in Indonesia and Burma. Yet to me it seems widely shared among contemporary social scientists, and I will assume its validity for the purposes of discussion here. ${ }^{1}$

A collection of essays entitled Emotions in the Field: The Psychology and Anthropology of Fieldwork Experience (Davies and Spencer 2010) addresses the point that fieldwork necessarily evokes a researcher's emotional responses. In his introduction to the volume, James Davies (2010) provides a useful overview of the relations between anthropology and psychology, highlighting in particular how these have inflected research methods. Michael Jackson (2010), in his contribution to the volume, anticipates some of what I wish to say here about the fact that a researcher's psychological make-up will affect the encounters that take place. Yet I want to proceed further along this path and suggest that when ethnographers consider in some depth what incited them to engage in fieldwork in the first place, that reflexiveness can enrich the account they later give of it. That is, since we have learned that all perspectives are partial, we can benefit by analyzing the origins as well as the distinctiveness of the take any one of us has on what we observe. Personal temperament, idiosyncratic history, neuroses, preoccupations-these constituent elements of every individual will necessarily affect the results of fieldworkers' experiences and the interpretations they make of those experiences. These personal specificities do not introduce unfortunate distortions, but rather particular idiosyncratic perspectives that, with any luck, are original and insightful.

To illustrate my point, I will proceed in what follows to set out, first, what an odd version of social relations fieldwork often, especially in its most 'classical' form, entails, that is, when undertaken in a place that is, for the researcher, geographically and/or culturally distant. Since fieldwork conducted in a language one has studied only in adulthood illustrates the challenging nature of the enterprise particularly sharply, I begin by focusing on language learning. I then consider what in my own childhood experience should have induced me to become both a committed language learner and an ethnographer. By searching in the recesses of my own psyche to see what might explain my attraction to the field of anthropology, and in particular to its longstanding commitment to fieldwork, I hope to provide clues as to the motivations of others, as well as myself, in taking on this role.

In the latter half of this article, I relate by way of example my experiences as an ethnographer in two very different settings: a Buddhist meditation retreat in Burma, and a men's naked yoga retreat in Texas. In the first case, I consider how deep-seated features of my own personality-necessarily culturally, not solely personally, inflected-highlight contrasts between what a middle-class, 
middle-aged white Western male is likely to seek out of his later life and what a middle-aged Southeast Asian male might wish to pursue, by way of contrast. In the second case, I consider how what I have highlighted about a Western preoccupation with forming social connections plays out among men whose relations are, to one degree or another, vexed. My larger purpose is to suggest that the preoccupations fostered by my personal experience led me in the course of those fieldwork encounters, and in further reflection thereafter, to ask some fairly fundamental questions about social relations, not just my own. Personally urgent questions about my own social relations led me, I wish to claim, to anthropological reflections of greater generality, and so of greater interest and import.

\section{Language Study as Fieldwork Mock-Up}

Learning languages, an ongoing obsession in my life, exemplifies the quixotic nature of the ethnographic endeavor, especially (but not only) as undertaken by anthropologists. Most people seem unaware of just how vast an investment of time learning a foreign language represents. A neurotic readiness to hear the difference between the sounds others make and your efforts to reproduce them, a vigilant alertness to the way people use specific words and phrases, the discipline to check words in the dictionary and to memorize vocabulary with unfailing regularity: everything about the enterprise requires discipline and determination directed toward learning how to imitate others. But the chances of success are limited. Coming to be only reasonably competent, but never totally so, at doing something-speaking intelligibly_that a great many people around you do without a thought, enabling them to interact effortlessly, unselfconsciously, and confidently, is the best most of us can hope for.

Learning a language means, for a fieldworker, acquiring a tool with which to seek both ethnographic insight and satisfying relationships. It is a necessary but by no means sufficient condition for attaining either of those ends: it may or may not turn out to bring much in the way of results. It's like needing a hammer to apply to a nail and getting started by going off into the woods to look for a good sturdy branch-and then wondering where you might find iron deposits.

I have studied a number of languages-four European and four Southeast Asian ones-and people find me fairly convincing at speaking them. But I always feel like I'm on thin ice, at risk at every moment of confronting a roadblock, encountering some hole in my vocabulary that will prevent me from being able to say what I intend. So speaking becomes a particularly focused instance of interaction with all its attendant anxieties. I remind myself that being grammatically correct hardly matters all that much. Since I will not be mistaken for a native speaker in any case, I need not worry about getting a word or a tense or a structure a bit off as long as communication continues apace. 
Ah, but pride refuses me this out. I once met an Indonesian couple living in Germany. They spoke German without any trouble. Indeed, it was the only language in which they communicated with their young daughter. But their fluency derived from their not bothering themselves with such fine points as tenses, grammatical gender, plurals, or cases-the things that make speaking German, for me, an endlessly tense high-wire act. I wished I could be similarly cavalier. But it was and remains out of the question. I am determined to become competent, no matter how great the odds against my doing so, as I aspire to smooth and effortless social relations conducted in the language of those around me.

\section{Fieldwork's Trials, and My Own}

Fieldwork induces with particular severity a language learner's feelings of incompetence. Despite the romantic aura that surrounds (or at least, prior to the crisis in representation, used to surround) the fieldwork of our anthropological forebears, the fact is that fieldwork inevitably entails social disorientation. That experience is pretty well assured when entering a community other than one's own: it will almost certainly give rise to embarrassment, boredom, irritation, and discouragement. Just ask anyone who has done it. It may well also result in insect bites, copious sweating or shivering with cold (maybe both), a diet over which you have little control, and intolerable noise. In my case, in Burma and Bali there was also the matter of lethally poisonous snakes.

This account may bring to mind pith-helmeted colonial officers more than contemporary anthropologists, many of whom carry out their field research in far less physically demanding circumstances. Nevertheless, to the extent that fieldwork means leaving behind one's familiar social and cultural environs and throwing oneself into a new milieu, and maybe having to do so in an unfamiliar language, the dislocation still usually applies. And so, then, does my question: what motivates someone to do it?

To focus the question more sharply, why did becoming an anthropologist seem to me, already at the age of 17 , without a doubt what I wanted to do? I find attending a cocktail party disquieting enough. Trying to fit in over months and years among people to whom I knew I could make no evident social sense and whose language I would never truly master: what could have made me think this would be rewarding, let alone fun?

The answer is at once obvious and disturbing. Failing to fit in at home-my imperfect gender performance as a boy troubled my mother, who tried to fix me, and baffled my father, who simply withdrew-somehow suggested to me, however inchoately, that things might go better elsewhere. My older brother Rocky fulfilled all gender requirements effortlessly: he was great at science 
and math, witty, athletic, and stubborn as hell. I was none of the above to an astonishing degree. We were all astonished, and dismayed. And I, knowing that none of this was going to change, was deeply disheartened. I set about learning foreign languages as soon as I could, and plotted getting to Europe after I heard my grandmother talking about her trips there. Rocky didn't need to go to Europe because he was doing fine right where he was: in small town (later becoming suburban) Connecticut, then Harvard, then Alaska. He engaged in wildly reckless behavior in high school with his skiing buddies. It's a surprise he survived those years, although he didn't survive that much longer. He died rock climbing on Ben Nevis in Scotland at the age of 25.

It was reckless in a different way for me, also in high school, to turn into a passionate opera fan. Although I have come to believe over the years that opera is petrified popular culture, in 1960s America it was to me, as well as my peers, arcane, snooty, and very foreign. To love it, as I truly did, while hating sports, was to set myself apart. Becoming a resident stranger in a village in Java a few years later was to repeat, in an exaggerated version, behavior I had already embarked upon well before: striving to forge a distinctive path when it was clear that following the normal one was beyond my ken. I was inventing a self, taking on a role (as a foreign newcomer in a village) that many people there might find intriguing, at least for a little while, but one that stood no chance of truly satisfying my emotional wishes because true intimacy was precluded from the start. (I knew even as a twenty-something that a romantic attachment in Indonesia was not likely to satisfy my long-term needs.) Nevertheless, I persisted, creating - in Java, then in Bali, then in grad school, back in Java, later in Burma-yet another marginal, self-effacing identity with which to re-enact the travails of my marginalized, effaced, and deeply lonely childhood. And eventually, less obviously but, I now see, also quite really, in my marriage. Repeatedly placing myself in situations in which I was forced to struggle mightily to try to find a way to interact effortlessly, unselfconsciously, and confidently meant that I acted out the compulsion to repeat with impressive, indeed textbook, doggedness.

\section{A Viscous Self}

I see a connection between my determined study of languages and my attraction to fieldwork. My alertness to what determines correct pronominal usage when speaking Southeast Asian languages pleases people when I'm there, although this is something everyone in the region spends their lives doing, so it doesn't impress them as much as I sometimes think it ought. Yet my ability to do fairly well at learning languages strikes me as one piece of a larger strain in my character: a certain malleability or even unfinished quality. This applies to my sexuality as well. I have always recognized my bisexual inclinations. They 
have induced feelings of tentativeness, ambivalence, a certain lack of focus. Yet that very lack of resolution, like a blurry image, suggests unexpected advantages with respect to both language learning and fieldwork.

I have in my time met many straight men who spoke a foreign language well, and being gay guarantees nothing with regard to ease in learning a foreign language. Nevertheless, many of the men I have met who did really well at mastering a foreign language, or a number of languages, were gay, and I have to wonder what might explain the link. ${ }^{2}$

I speculate that the link lies in a certain unfinished quality about many gay men's self, like a lemon pie filling that has almost but not quite set. I do not wish to imply a biological or pathological cause for this circumstance. I would attribute it instead to a young man's awareness, as the distance widens between what everyone expects of him and his own inclinations, that 'identity' has for him much less of the inevitable and solid about it than the viscous and malleable-that the self is to him more obviously a gradually accumulating sedimentation out of performance, as Judith Butler (1990) has proposed, rather than a costume taken on once and for all before walking out on stage. The fact that what is considered 'natural' does not come naturally to him, that what would make no sense to everyone around him (a disparity between what his body implies and where his desires drive him) imposes itself with such force on his every waking thought and, worse, his dreaming mind and uncontrollable body-all of this means that his sense of himself in the world may never quite gel. ${ }^{3}$ A possible if unanticipated consequence of his self remaining so plastic may lie in a certain facility with foreign languages. ${ }^{4}$

Or an inclination toward anthropology perhaps? Anthropologists have taken recently to accusing each other of overgeneralizing about-which is to say, stereotyping - the people we study. I am stereotyping 'us', anthropologists, not 'them', those others more usually subject to anthropologists' gaze, when I assume that many of my fellow anthropologists were drawn to the field because their social relations, like mine, feature some deep-seated conflicts, not necessarily concerning their sexuality but some difficulty in their ability to connect to others. Why else would anyone choose to engage in the exercise, usually disheartening and lonely, of trying to make one's way among strangers, and quite likely in a new language to boot?

The very fluidity I sense in my own self-the lack of integration into a consistent, self-confident individual-stands me in good stead when I am in Southeast Asia. In conducting fieldwork, my ability to let my own thoughts and feelings remain submerged turns out to be an advantage more often than a disadvantage. My interlocutors are more easily convinced of my genuine interest in their thoughts and lives and become accustomed to my disinclination to disagree with them or in any way put them on the spot. When real disagreement threatens, I seek cover. A monk I learned a great deal from in Mandalay offered to 
introduce me to a friend of his, a notoriously racist, hate-mongering monk who has repeatedly incited violence against Muslims. I couldn't see myself arguing with the monk but dreaded the moral compromise I would be making simply by sitting there listening to him in silence. I decided to turn down the offer.

No doubt many anthropologists escape the rigors imposed upon me by my peevish and demanding psyche. And few of them probably see in their ethnographic skills evidence of character flaws, as I tend to see in my own. Nevertheless, I'm sticking with my hunch that some unconscious glitch impels them to undertake the peculiar operation of putting what is obvious and normal-all those assumptions that make it clear how to get through the day, what anthropologists call 'culture' or 'habitus'-into question.

\section{Ethnographic Encounters}

To support my contention that an individual fieldworker's personal conflicts may be turned to analytic advantage, in what follows I draw on my own experiences in two very different settings: an 'insight' (vipassana) meditation retreat in Burma, and a men's naked yoga retreat in Texas. As I will explain, the first was physically extremely demanding, whereas the latter was socially so. Both were emotionally challenging for me, although in ways that greatly differed. Yet if only because it was the same psyche undergoing both experiences, the two contexts turned out to raise similar issues, ones that have long preoccupied me. Of course, these brief reports from the field allow me to speak for the most part only for myself-not what anthropologists usually wish or claim to do. Yet I hope to demonstrate the point I made above: that a fieldworker's personal concerns can provide analytic benefits.

These experiences took place over a period of a little more than a year, at a time when I was undergoing considerable personal disarray, although the matters I spent so much time turning over in my mind were ones I had wrestled with for much of my life. Still, in important respects, my many years of prior fieldwork in Southeast Asia informed the conflicting ways in which what I experienced affected me and the ways in which those experiences stimulated and irritated my psyche, as I will now try to show.

\section{A Buddhist Meditation Retreat}

We were instructed to focus on our breathing. We should sit however we felt comfortable and then think exclusively about the air as it entered and exited our nostrils. Just that area: immediately inside our nostrils, immediately outside them, and the area between our nostrils and our upper lip. We were to 
breathe naturally; we were not to try in any way to alter our breathing. We should think of nothing else.

We would fail. Our minds would wander: they would go here, they would go there. (In Burmese, one says, “They go yonder, they come hither.”) That was inevitable. We were not to become discouraged. We were not to become impatient. We were not to become angry. Each time our mind wandered, we were simply to note that fact, and bring our mind back to our breathing, to that small area immediately inside, immediately outside, and immediately below our nostrils.

I found in the course of the first day that, as anticipated, my mind wandered ceaselessly and my legs ached horribly. At the end of the first day's long afternoon sessions, a total of four hours, it occurred to me as I walked back to my room that even though I was doing badly at controlling my thoughts, the failing and regrouping, failing and regrouping, failing and regrouping were essential. It was not just that one was trying as hard as possible to focus, but that one was forgiving oneself for being unable to do so. Maybe this was why my most recent psychotherapist in the US had suggested somewhere along the line that meditation might prove useful. ${ }^{5}$ Forgiving myself is something I have always had trouble doing; I am painfully aware of my shortcomings, and I have let many people down. I never stop disappointing myself.

Trying on that first day to cope with the terrible pain in my legs, pain that shifted as I shifted position but that never went away, I found that sometimes my eyes, already closed, would seem to sink into greater darkness as they felt some sort of pressure placed upon them. That hurt a little bit. But within a minute or so, the pain in my legs, back, shoulders, arms, and/or neck seemed to lessen. Along with it came some sort of biochemical effect-adrenalin, maybe, entering my system. I wasn't sure. It occurred to me that if this sort of relief, only more so, was what drug addicts felt when they got their fix, I could appreciate the appeal. If, furthermore, their agitation was like what I felt before the relief came, only more so, yes, I could understand how great the compulsion to get relief would be. I hadn't anticipated that meditation would grant me insight into addiction. I also came to understand that the pain was, for me at least, an essential part of this enterprise, because it was the pain that made one's mind focused; it was the incentive to think intensely about the matter at hand.

At the time I signed up for that first meditation retreat, I had lived about 8 out of my 62 years doing anthropological fieldwork in Burma and Indonesia. I had always resisted partaking in meditation. There isn't a spiritual bone in my body, and I saw no point. Still, I needed to know, for ethnographic reasons, why Burmese made so much of the practice. I was also motivated by more personal goals. I had been divorced for only a year and still found myself thinking obsessively about what came before and what came after the end of my marriage. What would become of me now? Maybe meditation would help me still my thoughts and assuage my pain. 
Ten and a half hours a day sitting on the floor with my eyes closed was physically painful and emotionally harrowing. My mind never ceased wandering: to Burma's recent tumultuous contest between the military and Daw Aung San Suu Kyi, a wisp of a woman with nerves of steel who stood for tolerance and peace and attributed her fortitude during years of house arrest to her practice of meditation, ${ }^{6}$ as well as to events in the monastery in Mandalay where I was then living as a lay observer. It also made me ruminate about matters-my many years of marriage, now ended; my earlier stays as a young researcher in Indonesia; and, much further back, my childhood of material comfort and emotional neglect-at extended, and often distressing, length. The retreat felt less like conventional fieldwork than the pain-inducing excavation of my unhappy past.

A meditation retreat in U Goenka's Vipassana Meditation tradition would actually appear to pose insuperable obstacles to doing anything resembling fieldwork. After all, meditators must not only sit in meditation with their eyes closed during most of their waking hours for 10 days. Throughout the course, from the evening before the first sitting starts at 4:30 in the morning, until mid-day on the tenth day following, they are forbidden to read, write, or speak. Even during brief breaks (for simple meals, eaten at dawn and before noon each day, and in between sittings), they are enjoined not even to look at each other.

An anthropologist who participates in such a retreat can observe almost nothing: observing others, as noted, contravenes the spirit of the enterprise. And writing up notes would mean breaking a clearly enunciated rule. An anthropologist in this instance can fall back only on himself or herself because all other selves are explicitly off-limits. Solipsism isn't the danger here. It is both the obligation and the point. ${ }^{7}$

But then reflexivity, which many anthropologists believe to be crucial to the appropriate conduct of fieldwork and to the ethical interpretation of its results, is precisely what 'insight meditation' claims to be about. What this particular meditation stream's leader, U Goenka, tells us that we can gain by meditating is an understanding of ultimate truths about ourselves, an understanding that will enable us to engage much more effectively-with greater compassion and greater clarity-with others. Who among anthropologists would dismiss such a goal, for themselves as well as for members of any community they find themselves in?

Engaging in this exercise at this particular point in my life highlighted the contrast between what a Burmese man my age would seek-an impressive and dignified demeanor with which to win others' respect-and my still intense yearning for connection. The 'insight' that U Goenka promotes, along with many other purveyors of Buddhist understandings, is a perspective on our lives conducive to such equanimity, one that I am inclined to label 'imperviousness', in the face of impermanence.

A conversation I had with one of the participants after the retreat was over made the contrast particularly vivid. When the ban on speech was lifted on the 
tenth day, I made a point of speaking with a middle-aged Burmese man who had been sitting next to me throughout the retreat. I couldn't help but notice that whereas I was frequently obliged to shift position in order to relieve the physical pains I suffered, he did not. Not once. (I could not see him, since my eyes were closed. But I could hear anyone in my vicinity move.) He would sit down, cross-legged, at the start of each meditation period and not move until the session ended. Speaking with him, I found him interesting and articulate and so arranged to meet him at a later time when I went to Rangoon, where he lived. At a certain point in our conversation, I mentioned to him that I had undergone much emotional travail, and at least once each day tears ran down my cheeks. He responded, "Yes, some people report such feelings. You just have to let them go."

The ease with which he said this-not unfeelingly or resolutely, but rather quite matter-of-factly-impressed me. It summed up much that distinguished my sense of what well-being would mean for me versus what it would mean for many Burmese men I knew. Similar to what Julia Cassaniti (2015) has very movingly described as the need or, better, the skill with which people in northern Thailand dealt with setbacks by denying their force, I found among many middle-aged Burmese men a greater concern with their steadfast pursuit of Buddhist goals than any holes that pursuit might make in their personal relationships. This particular man explained that he hoped eventually to become a monk. His wife would stay in contact with their children and grandchildren, but he would no longer concern himself with his close kin. He would instead focus on observing the precepts enjoined upon a Buddhist monk, while engaging in a good deal of meditation. He would, in sum, let the world go.

Alone after 25 years of marriage and with my two daughters now grown, I could do things like spend close to a year living in Buddhist monasteries in Burma doing anthropological fieldwork. But I hated feeling so much alone and yearned to have someone at the center of my life, someone for whose life I would in turn provide an essential point of repair. Clearly, my goals were quite diametrically opposed to those of my thoughtful Burmese interlocutor.

Theravada Buddhist doctrine claims that the cure for the yearning I experience lies not in making the connection happen but rather in extinguishing the yearning. ${ }^{8}$ Buddhism recommends, in a word, detachment. I should prepare for the approaching loss of my powers and eventual death by reducing my investments in the world, in others, in goals, projects, plans, promotions, raises. For sure, the frenzy of grasping can only cause restlessness. I have long understood that good friends bring satisfaction, whereas material goods do not. Hostility and negative feelings of all sorts will cause suffering: yes, I can appreciate that, too. But so, Buddhism asserts, will deep feelings for other people whose company I could too easily come to depend on. Since the nature of all existence is flux and dispersal, such dependence upon conditioned things is ill-advised. I see the logic in this. But I balk. If I give up yearning, is what remains serenity 
or resignation? If I don't cling to the promise of a longed-for attachment, what's the point? Oh, that's right: I should stop looking for a point.

It is clearly the case that the less we invest in others, the less pain we will feel at their passing. In Buddhist Burma, to break attachments wins praise, at least when done with a view to one's spiritual betterment-and when done by a man. Whether a woman should do so generates much argument. ${ }^{9}$ Yet my own inclination runs contrary to the Buddhist position, and I believe this is true for a great many people, certainly for those Westerners who find psychotherapy's claims convincing. For me, the only bulwark against despair consists in the relationships we forge with others, and the only solace for when people whom we care about are lost to us lies in the other people to whom we can, if we are lucky, still turn.

\section{A Men's Naked Yoga Retreat}

After the meditation retreat, which was followed a couple of months later by the conclusion of 10 months of fieldwork in Mandalay, I returned home to Texas and did the logical opposite of the Burmese meditation course: I signed up for a three-day men's naked yoga retreat in the Texas Hill Country. Desires, so carefully disvalued and tamped down in Burmese meditation, were as much on display at this Texan retreat as bodies, and I wondered, as a bisexual male who had long been married and had expected to stay that way, what mine actually were. For the moment, I seemed to find masculine company easier and more pleasurable than women's, but gay sex disappointing. Maybe I just hadn't got the hang of it. But if the point is pleasure and excitement, should one have to work at it?

I joined in activities I found exciting and repellent by turns. There were partner yoga sessions, zumba dance practices, and various pretexts for contorting our naked bodies into awkward postures. I am not a joiner but forced myself to join nonetheless. My rationale for doing this retreat was to explore new paths, casting off inhibitions with my clothes. Shame pursues me at every turn and always has. Is it possible to face down shame? Does acting on voyeuristic and exhibitionist impulses among like-minded peers pose an alternative path to self-acceptance? Or is it just silly?

Particularly telling was a meditation session in an Indic style held one afternoon. We sat on the sand of a volleyball court, cross-legged, while a man evoked in a steady, quiet voice a series of chakras, spots along the body from what I took to be somewhere just above the anus, near the pubic bone, behind the navel, and so on up the spine and out the top of our heads. And then back down again. At each spot we were to visualize a color as we heard about the associated function or emotion: sexual energy, empathy, love, wisdom. I have heard this series 
of chakras several times, and none of it ever sticks in my head. Talk of energy flows, whether in the Indic or the Chinese tradition, makes no sense to me.

Yet it became clear to me in this instance, as in Burma, that what matters is not subscribing to a particular take on the inner workings of the human body-cum-spirit but rather finding a way to focus the mind and quiet its ceaseless, jumpy exertions. The studied recitation of an esoteric set of labels was intended to help us drive other thoughts out of mind, to bring our attention under our control, and then to keep our attention sufficiently distracted-with standardized, generic references to spots in our bodies, colors, types of spiritual experience, and so forth-in order to establish some distance between the claims that our past and future constantly make upon our attention in the present moment, distracting us from it.

At the end of the meditation session, we were told to place one hand on the earth and to feel love around us, among us, within us. I recognized a translation of the Buddhist habit of ending meditation by radiating 'loving kindness'. Yet I had the impression that the gesture took on quite a different cast here. We were being urged to overcome shame, to abandon self-loathing, to trade in negative notions of ourselves for more positive, forgiving, self-accepting ones. We were not Lear's "naked, unaccommodated man," but rather naked, presumably gay men, seeking to find ways to accommodate our selves to ourselves. And then, for some of us at least, to forge meaningful connections with other men.

Thus, despite an apparent affinity with the meditation retreat in Burma, this hour's meditation in a neo-Indian style was actually very remote from what goes on in Burma, since it meant substituting self-affirmation for Buddhism's self-effacement. ${ }^{10}$ Burmese Buddhists would find all rhetoric of self-validation, no matter the nature of one's desires, out of place. Sexual desires obstruct spiritual progress and so should be put aside, while shame and self-loathing, along with sadness and for that matter happiness and excitement, should simply fall away as one's insight grows.

In Texas, on the contrary, many of the men attending the retreat seemed invested in forming some sort of connection with others, and here lay the truly crucial contrast with the Burmese meditation retreat. Some of the Texas yogis were happy to engage in short-term, casual sexual play: a fair bit of semen got spilled around a picnic table in an endeavor I as an accidental bystander had to make some effort not to judge harshly. (It does not surprise me that middleaged men should remain highly sexed. It was only making it so publicly obvious that put me off.) Other men seemed to hold out for something more long term, whether that meant for a night or a period extending beyond the retreat itself. But no surprise there either: the validation of sexual and romantic relationships that so pervades contemporary American popular culture, and more serious discourse in the US as well, induces longing in many men, including myself, even if much of our behavior sets up obstacles to its satisfaction. That 
is, the absence of such relationships is experienced by many American men not as detachment but rather a lack, or a failure. The Buddhist meditation retreat was an exercise intended to enable its participants to overcome such investments and attendant goals. Facing a lack, one can try either to fill it or, in the solution Buddhism proposes, to dismiss it as no such thing, as nothing.

I reflected on sex rather than engaging in it at the men's naked yoga retreat, but it was definitely in the air and had to be confronted. In Southeast Asia, what matters in sex is only whether you penetrate or get penetrated, not the sex of your partner. But males in both Southeast Asia and the West seem to have trouble getting beyond touch to seeking attachment. Touch for guys often seems not to express connection but rather stave off its risk, just as nudity suggests intimacy but may only substitute for it. I had glimpsed what it might be like to connect deeply with someone just after my divorce came through. That experience only added to my confusion. Is it reassuring to still feel capable of such excitement? Or is it only undignified as an older man to be smitten and then devastated by a rejection whose coming I fully and rightly anticipated?

What if I chose instead the Buddhist prescription and let go of sexual and romantic goals in my life, satisfactions that have remained, since my divorce, purely virtual? Determining the exact nature of my desires wouldn't matter if they simply lifted like a thick morning fog. I'm not sure. I wonder, as most people do, how I would fill my days were I to retire. I wonder, along the same lines, what would substitute for my addiction to desire-by no means only sexual, although sex certainly figures into my romantic longings for a loving relationship-if I lost this compulsive yearning. It would be like watching my hair lose its color, which is in some ways worse than its falling out (both of which are occurring). Or coming to think of my penis as just another part of my body, like an ear lobe or one of my big toes. Taking on this detached attitude toward my own sexuality and body parts would no doubt stabilize my moods, free my mind to think through ideas more clearly, and maybe even give my complexion the glow that many South Asians believe retaining semen accords a man.

My life suggests that I care intensely about maintaining my own autonomy. I married late (at the age of 36), and divorce has returned me to the complete control over my life that I enjoyed and bewailed for all the years between college up until my marriage. Yet I feel a great lack in my life in finding myself alone-as though attachment was not the risky and illusory condition Buddhism teaches us to be wary of. I know several men who are alone and, having loved and moved beyond a certain number of partners, seem to feel little need to start the whole undertaking up again. Is it that they never quite found the right way to establish a truly satisfying attachment? Or is it that, having enjoyed the satisfactions that attachment granted them, they are now ready to appreciate, serenely and calmly, the complementary pleasures of their autonomy regained? Have they attained some version of Buddhist detachment? 
Watching the other men at the naked yoga retreat, and watching myself there, I swung back and forth between a distancing irony and a heartfelt empathy. They were struggling as I was struggling with yearning, shame, hope, and randiness. We were all opting for alternative solutions, although not necessarily doing so consistently. I forced myself to join conversations at meals or in the pool or at the open fire pit at night, trying as hard as I could to feign assurance in situations I found very challenging: sometimes awkward, because I didn't know anyone present and had to impose myself on the scene; sometimes truly off-putting, because some group activities demanded a level of physical touch I had trouble tolerating. Yet these were simply new variants on the familiar theme of fieldwork's stresses. Pretty early each night I would retire to my tent, alone, disappointed, relieved, resigned. It all seemed wildly antinomian and in the end altogether familiar. I was unattached, yes, but not yet detached: ironic, distanced, and aware of how much that irony was a defense, all while seeking closer connections. I was once again back in the field.

\section{Autonomy, Attachment, and Sex}

What is all the hullabaloo about sex? Why is it something people pretty much everywhere I have lived, or men, at least, ${ }^{11}$ think about obsessively and talk about only obliquely, allusively but rarely seriously, with singular but disavowed focus, anxiety, and a hefty clutch of contradictions? The issue affords as good a place as any to consider more explicitly how contrasts between American naked yogis and Burmese Buddhist meditators point to larger matters of cultural comparison that I have made passing reference to above but I now wish to broach more directly.

That there are biological reasons for sexuality's power to distort our thinking and affect our actions is clear. But why the weird silence about it, as well as (as per Foucault 1978) the compulsive but always euphemized or aestheticized or otherwise deflected and misleading talk?

I infer that sex looms so large in people's thinking and so pervasively and evasively in people's speech because it brings into focus with such intensity our contradictory desires to connect deeply and powerfully with others and to keep those others safely at bay: to feel at once deeply bonded and unbound. There is a spectrum spanning the distance between autonomy at one end and attachment at the other that is implicit in any individual's life. It is difficult to find any single point along that spectrum that can enduringly satisfy any of us. And when I use 'our' and 'us' here, I refer to us humans. These contradictory desires strike me as existential and thus must be addressed by any group of humans in one way or another; in so doing, certain choices are promoted over others in each individual's decision making. 
Although I am ill-equipped to speak for how women, either in Burma or the US, deal with these conflicting wants, particularly with respect to their sexuality, I will venture generalizing comments about men. A man can experience sexual intercourse as an affirmation of his power or a dramatization of his vulnerability, a demonstration of his control or an indication of all the many threats to his autonomy. Or all of the above at the same time. It isn't just that his performance may prove lacking. It's that to the degree he lets his feelings intensify in step with the stimulation of his nerve-endings, he bargains away autonomy for interdependence, freedom for connection, the safety of selfreliance for the excitement and risks of relatedness (cf. Keeler 2017: 219-227). Just how advisable is it to strike such a deal? Or if sex is not to be dismissed altogether-as it is for Buddhist monastics-just what means can be found to stave off impressions of an unwonted compromise of a man's vaunted autonomy even as he wins some satisfaction of his sexual wants through connection?

In many places, a man insulates himself from attachment's Sirens by taking many sexual partners, preventing any one of them from coming to matter too much to him. Such was the habit of Southeast Asia's royal males, or indeed most elite males (and a fair number of humbler-status ones, as well) in the region. ${ }^{12}$ Buddhism's solution is straightforward but opposite: giving up sex altogether. Monks must obey a great many rules, but the one that seems most salient to people's thinking in Burma is the injunction against engaging in sexual behavior of any kind. Novices (boys living as monastics up to the age of 19) are allowed to bare their bodies completely at no time whatsoever, even if they are alone. Only when they are older, as ordained monks, can they remove all of their robes at once-provided no one of either sex can see them-on the grounds that they will have grown more practiced at staving off all sexual impulses. Lay people are subject to no such absolute prohibitions (although Burmese are very prudish about their bodies). Yet they are expected to outgrow their sexual desires the way that some people outgrow their allergies.

For Burmese Buddhists, my continued desires for attachment attest to my continued but inappropriate and suffering-inducing investment in illusory satisfactions. I remain, along with the rest of my fellow naked yogis, spiritually unaccomplished, still too invested in attachments to be able to attain true autonomy, which is to say, detachment.

\section{Autoethnography and Me}

I have tried to demonstrate in this article that my idiosyncratic experiences, including the personal difficulties I have undergone throughout my life, have sensitized me to certain issues that proved relevant to my ethnographic fieldwork in two very different settings, and to the thinking that each of them gave 
rise to. Of course, it is quite possible to set forth these ethnographic observations and analyses in less personally revealing ways. In other writing based on my long-term fieldwork in Indonesia and Burma, I have done just that (e.g., Keeler 1987, 2017). Yet I believe that writing in a more personal voice adds a certain vividness, even urgency, to an account.

I do not claim to be forging an entirely new path. There is a rich and growing genre of 'autoethnography', and I have felt encouraged to write this article in the way that I have in part by following certain autoethnographers' examples. Such renowned anthropologists as Lila Abu-Lughod (1986) and Ruth Behar (1996; cf. Toor 2017) have made impressive contributions to anthropological literature that could be assimilated to the autoethnographic enterprise. However, the matter of how to include sustained attention to ethnographers' own personal experience in their reporting has been debated more consistently in recent decades by sociologists, especially those who acknowledge a special debt to the symbolic interactionist tradition.

Without trying here to summarize all of what is at this point a considerable literature, I would point out consistent questions that sociologists have raised. First, what are the most effective ways to engage the interest of a reader in whatever ethnographic material a social scientist wishes to report? Linked to that question is whether ethnographers should feel restricted to reporting straightforward facts or might exercise greater authorial freedom, such as introducing their own personal feelings and reactions, particularly those they experienced in the course of their research (Adams 2006; Anderson 2006a, 2006b; Ellis 2012, 2017; Ellis and Bochner 2006; Ellis et al. 2011); creating composite (rather than simply anonymized) individuals (Müller 2016); or writing fiction (Beatty 2009, 2010).

I have elected to draw in part upon autoethnographic methods of the first sort. But I have done so while pairing my account with more analytic remarksabout the contradictory pull of autonomy and attachment and contrasting ways of addressing that existential issue-than is often the case in autoethnographic writing, where much by way of commentary seems sometimes to be shunned. ${ }^{13}$ I have tried in fact to illustrate the value of combining personal introspection with ethnographic observation and analytic remarks in order to suggest that the quirks and rough spots of an individual's psyche-in this case, my own-may help to discern and grapple with anthropological issues of greater significance. ${ }^{14}$

\section{Conclusion: The Psyche as Baggage or Tool}

Does the fact that a psyche gets packed along with all the rest of every anthropologist's gear compromise the value of the results? The outrage that the publication of Malinowski's (1967) diary generated seems to reflect shock at the 
simple truth that a man who found himself living alone in a tent on the beach in an alien community a great distance from his war-ravaged home-having to learn a language and trying to ingratiate himself among people with whom he had no prior connection-would experience mood swings, disarray, improper thoughts, and sexual fantasies of an unworthy and even racist character. As if none of us right-thinking progressives would ever respond to stress in unattractive ways. We have nabbed Malinowski in the act of having an unconscious. Pace Freud, we are much too virtuous and good in our commitment to social justice to be susceptible to moments of unbecoming impulses, no matter how great the disarray and vulnerability we might sometimes feel. And what right does a straight, white, educated male have to feel vulnerable anyway?

Rather than decry the pitfalls and distortions that personal foibles or character flaws introduce in anthropological research, I suggest that we face up to them-and exploit them. Psychotherapists, after all, must work vigilantly to make sure that they do not respond inappropriately to a patient's remarks because of any way these might chafe against the therapist's psyche. Yet therapists must at the same time allow themselves sufficient freedom to respond intuitively and feelingly to their patients if the therapeutic encounter is to feel like a collaborative and constructive endeavor rather than, say, surgery without anesthesia. If an anthropologist finds that fieldwork incites reflection about interpersonal relations, then such reflection ought to lead to greater insight into his or her own life and social relations at home, not just in the field. And such insight might well turn out to provide help-not just academic knowledge but real advances in understanding - to readers who themselves spend time pondering challenges they face in their own lives.

In other words, thinking deeply about other people's social relations, which lies at the core of at least some anthropological research, should induce us to think in new ways about our own, even the idiosyncratic, maddening, neurotic, and nagging parts. It isn't just that the personal is political, which is one way of phrasing some of the critiques of anthropology. It is also that the ethnographic is always deeply personal. To the degree that we own up to that fact, we augment not only our appeal to a general readership. We also increase the likelihood that we can act on our presumable commitment to the alleviation of human suffering by letting others see how we have tried to deal with our own. This would confirm the value not just of ethnography, but of the social sciences more broadly. At a time when anthropologists, along with all academics, are being encouraged-or compelled-to explain why what they do matters, finding ways to connect to readers' deepest personal concerns might provide one particularly effective response.

We should indeed consider the power implications of the interactions we enter into, as recent anthropologists have felt duty-bound to do. But we should also consider how what we learn about social relations and the variety of forms 
they can take proves pertinent to our own lives-to our own ongoing concern with who we are, what we want out of our life, and how we intend to fill out the rest of it. I am not suggesting that academic analysis is dry or invalid or beside the point. Only that what we learn in our experience someplace else can, and should, touch us very, very deeply. It is never 'merely' academic, and might prove equally touching, even if only vicariously so, to people who come up against some of the same questions or undergo some similar forms of distress in the social relations they enter into at home. If my ruminations induce some readers, such as ethnographers, or observers or practitioners of meditation, or people who ponder persistent or repeating conflicts in their social relations, to resonate with this exercise, I believe I will have proved my point.

\section{Acknowledgments}

This article is based upon a longer memoir. Jason Cons, Mark Johnson, Kathleen Stewart, and Pauline Turner Strong have read portions of that memoir, as well as earlier drafts of this article. I am grateful to all of them for their comments and encouragement. I also wish to thank two anonymous reviewers and Martin Holbraad for their acute suggestions for revision.

Ward Keeler teaches anthropology at the University of Texas at Austin. His publications include books and articles about the performing arts, language, gender, and hierarchy in Indonesia and Burma; CDs of classical Burmese music; and a translation of a recent Indonesian novel. His most recent book is The Traffic in Hierarchy: Masculinity and Its Others in Buddhist Burma (2017). He has benefited from recent fellowships awarded by the Asia Research Institute at the National University of Singapore, the International Institute for Asian Studies in Leiden, the Stockholm University Department of Anthropology, the Institute for Advanced Studies - Nantes, and the Hanse-Wissenschaftskolleg in Delmenhorst, Germany. E-mail: ward.keeler@gmail.com 


\section{Notes}

1. The notion of how an individual is shaped by experience-in what ways, to what effect-is of course deserving of close study, and much interesting work in anthropological accounts of the person, the self, and the emotions implicates the point. My purpose, here, however, is to focus more on the person of the ethnographer than on the persons an ethnographer encounters, although I will touch on the topic briefly in comparing my own investments to those of people I know in Southeast Asia.

2. I find some confirmation of this impression in an intriguing piece about virtuoso language learners in the New Yorker that includes the following: "An extreme language learner has a more-than-random chance of being a gay, lefthanded male on the autism spectrum, with an autoimmune disorder, such as asthma or allergies" (Thurman 2018).

3. My comments on the experience of growing up gay (or in my case, bisexual) may seem dated, reflecting an era (the 1950s and 1960s) when intolerance for gender diversity was much greater than it is today. Nevertheless, conversation with contemporary young people in the US persuades me that, like myself, a good number of them experience some measure of disarray and often real distress, particularly if they have conservative parents.

4. Southeast Asians lay much less store by an authentic, original, integrated self than Westerners do, and their languages demonstrate the fact. Every person in Java or Bali or Burma, to speak of the societies I know well, takes on a distinct set of gestures, sentiments, and lexical items according to his or her social standing relative to that of others present in any given encounter. All of this receives vivid illustration in the proliferation in their languages of first- and second-person pronouns. How an individual refers to him- or herself, how one says 'I', depends entirely on the 'you' who is being addressed, and the languages of Indonesia and Burma I know offer up a range of variant items equivalent to those pronouns (similar but much more varied than tu and vous in French). Despite the range of pronominal options, which would appear to cover all possible situations, speakers often avoid their use, opting instead to label themselves in an appropriate manner by substituting for 'I' terms such as 'Son', 'Daughter', 'Student', 'Teacher', or 'Mr. Village Headman'. The same terms could also be substituted, according to the identity of the two speakers, for the pronoun 'you'.

5. This psychotherapist was one in a long series. My mother was a psychiatric social worker and had begun taking me to therapists early on in light of my obvious difficulties.

6. Daw Aung San Suu Kyi's performance as Burma's civilian leader in recent years has shown her shortcomings as a politician, a point I cannot pursue here (cf. Wade 2017).

7. I am not the first to remark upon the difficulty surrounding ethnographic reporting on meditation. Two Western anthropologists who are also practitioners of meditation, Gustaaf Houtman (1999) and Ingrid Jordt (2007), have 
undertaken long stints in Burma, and they have published enlightening but less personally inflected analyses of meditation. Another Western anthropologist and sometime Theravada Buddhist nun, Joanna Cook (2010a, 2010b), has published accounts about her experiences in Thailand. Her contribution to the above-mentioned collection, Emotions in the Field, shows her to be more thoroughly trained in and more benefited by the experience of insight meditation than I can claim. A particularly vivid evocation of the experience of meditation can be found in Faith Adiele's (2004) memoir, Meeting Faith: An Inward Odyssey. It was the late, much-lamented Steve Collins who drew my attention to this arresting memoir.

8. 'Buddhism' refers to an enormously varied and complex stream of ideas and practices. My knowledge of 'it' is restricted largely to Theravada Buddhism as practiced in Burma.

9. On the ambivalent attitudes toward Buddhist nuns in Burma, see Kawanami (2013) and Keeler (2017: 225-231).

10. Specialists would counter this description. It might be more appropriate to speak of 'self-surpassing', particularly in light of Buddhist doctrine's insistence upon 'non-self'.

11. I am not in a position to say much about women's views in places where it would be inappropriate for me to speak with women about such matters, although I have discussed other, more neutral topics with both laywomen and nuns in the course of my research in Burma and Indonesia alike.

12. With regard to the Thai case, see, for example, Barmé (2002).

13. Contrasting positions on this score are exemplified in the contretemps between Anderson (2006b) and Ellis and Bochner (2006).

14. There is actually a surprising disjunction between the current anthropological interest in affect theory (e.g., Berlant 2011; Cvetkovich 2012; Stewart 2007) and the long-standing interest among sociologists in the potential of attending to feelings when engaging in ethnography. Although the discussion of autoethnography among sociologists focuses largely on ethnographic methods and the dialogue on affect among anthropologists and cultural studies specialists focuses on 'public feelings', a shared concern with feeling makes for a good deal of overlap. Yet that overlap has stimulated rather little conversation across disciplinary boundaries. This gap is illustrated in a special issue of The Anthropology of Consciousness. In the editors' introduction, entitled “Toward an Anthropology of Affect and Evocative Anthropology," written by Ian Skoggard and Alisse Waterston (2015), no reference whatever is made to the sociological literature on autoethnography. 


\section{References}

Abu-Lughod, Lila. 1986. Veiled Sentiments: Honor and Poetry in a Bedouin Society. Berkeley: University of California Press.

Adams, Tony E. 2006. "Seeking Father: Relationally Reframing a Troubled Love Story.” Qualitative Inquiry 12 (4): 704-723.

Adiele, Faith. 2004. Meeting Faith: An Inward Odyssey. New York: W.W. Norton.

Anderson, Leon. 2006a. "Analytic Autoethnography." Journal of Contemporary Ethnography 35 (4): 373-395.

Anderson, Leon. 2006b. "On Apples, Oranges, and Autopsies: A Response to Commentators." Journal of Contemporary Ethnography 35 (4): 450-465.

Barmé, Scot. 2002. Woman, Man, Bangkok: Love, Sex, and Popular Culture in Thailand. Lanham, MD: Rowman \& Littlefield.

Beatty, Andrew. 2009. A Shadow Falls in the Heart of Java. London: Faber \& Faber.

Beatty, Andrew. 2010. "How Did It Feel for You? Emotion, Narrative, and the Limits of Ethnography." American Anthropologist 112 (3): 430-443.

Behar, Ruth. 1996. The Vulnerable Observer: Anthropology That Breaks Your Heart. Boston: Beacon Press.

Berlant, Lauren. 2011. Cruel Optimism. Durham, NC: Duke University Press.

Butler, Judith. 1990. Gender Trouble: Feminism and the Subversion of Identity. New York: Routledge.

Cassaniti, Julia. 2015. Living Buddhism: Mind, Self, and Emotion in a Thai Community. Ithaca, NY: Cornell University Press.

Clifford, James, and George Marcus, eds. 1986. Writing Culture: The Poetics and Politics of Ethnography. Berkeley: University of California Press.

Cook, Joanna. 2010a. "Ascetic Practice and Participant Observation, or, the Gift of Doubt in Field Experience.” In Davies and Spencer 2010, 239-265.

Cook, Joanna. 2010b. Meditation in Modern Buddhism: Renunciation and Change in Thai Monastic Life. Cambridge: Cambridge University Press.

Cvetkovich, Ann. 2012. Depression: A Public Feeling. Durham, NC: Duke University Press.

Davies, James. 2010. "Introduction: Emotions in the Field." In Davies and Spencer 2010, 1-31.

Davies, James, and Dimitrina Spencer, eds. 2010. Emotions in the Field: The Psychology and Anthropology of Fieldwork Experience. Stanford, CA: Stanford University Press.

Ellis, Carolyn. 2012. "The Procrastinating Autoethnographer: Reflections of Self on the Blank Screen.” International Review of Qualitative Research 5 (3): 333-339.

Ellis, Carolyn. 2017. "Sleeping Around, With, and Through Time: An Autoethnographic Rendering of a Good Night’s Slumber.” Qualitative Inquiry 23 (4): 287-299.

Ellis, Carolyn, Tony E. Adams, and Arthur P. Bochner. 2011. "Autoethnography: An Overview." Forum Qualitative Social Research/Sozialforschung 12 (1). http:// nbn-resolving.de/urn:nbn:de:0114-fqs1101108. 
Ellis, Carolyn, and Arthur Bochner. 2006. “Analyzing Analytic Autoethnography: An Autopsy.” Journal of Contemporary Ethnography 35 (4): 429-449.

Foucault, Michel. 1978. The History of Sexuality. Vol. 1: The Will to Knowledge. Trans. Robert Hurley. London: Penguin Books.

Houtman, Gustaaf. 1999. Mental Culture in Burmese Crisis Politics: Aung San Suu Kyi and the National League for Democracy. ILCAA Study of Language and Cultures of Asia and Africa Monograph Series No. 33. Tokyo: Tokyo University of Foreign Studies, Institute for the Study of Languages and Cultures of Asia and Africa.

Jackson, Michael. 2010. "From Anxiety to Method in Anthropological Fieldwork: An Appraisal of George Devereux’s Enduring Ideas.” In Davies and Spencer 2010, 35-54.

Jordt, Ingrid. 2007. Burma's Mass Lay Meditation Movement: Buddhism and the Cultural Construction of Power. Athens: Ohio University Press.

Kawanami, Hiroko. 2013. Renunciation and Empowerment of Buddhist Nuns in Myanmar-Burma: Building a Community of Female Faithful. Leiden: Brill.

Keeler, Ward. 1987. Javanese Shadow Plays, Javanese Selves. Princeton, NJ: Princeton University Press.

Keeler, Ward. 2017. The Traffic in Hierarchy: Masculinity and Its Others in Buddhist Burma. Honolulu: University of Hawai'i Press.

Malinowski, Bronislaw. 1967. A Diary in the Strict Sense of the Term. London: Routledge and Kegan Paul.

Marcus, George E., and Michael M. J. Fischer. 1986. Anthropology as Cultural Critique: An Experimental Moment in the Human Sciences. Chicago: University of Chicago Press.

Müller, Sophie M. 2016. "Becoming the Phenomenon? An Alternative Approach to Reflexivity in Ethnography.” Qualitative Inquiry 22 (9): 705-717.

Skoggard, Ian, and Alisse Waterston. 2015. "Introduction: Toward an Anthropology of Affect and Evocative Anthropology.” Anthropology of Consciousness 26 (2): 109-120.

Stewart, Kathleen. 2007. Ordinary Affects. Durham, NC: Duke University Press.

Thurman, Judith. 2018. "The Mystery of People Who Speak Dozens of Languages." New Yorker, 3 September. https://www.newyorker.com/magazine/2018/09/03/ the-mystery-of-people-who-speak-dozens-of-languages.

Toor, Rachel. 2017. "Scholars Talk Writing: Ruth Behar.” Chronicle of Higher Education, 23 April. http://www.chronicle.com/article/Scholars-Talk-Writing-Ruth/ 239847.

Wade, Francis. 2017. Myanmar's Enemy Within: Buddhist Violence and the Making of a Muslim 'Other'. London: Zed Books. 